the former, any tetrahedron and any unit point are shown to fix a system, and the coordinates are interpreted as anharmonic ratios, thus justifying the name projective coordinates. Projection is defined as a $(1,1)$ correspondence between the elements of any two entities, when the correspondence is defined by a system of linear equations with a non-vanishing determinant. In the second added article the projective theory of distance and angle are treated, thus justifying the earlier classification of quadrics. The discussion is also outlined for non-euclidean space, but the treatment is so brief that it can hardly be of assistance to the reader.

The chapter on confocal quadrics contains three added notes which connect the theory of confocal surfaces with that of poles and polars with regard to the absolute circle, and a number of proofs are simplified by means of duality. Use is made of the contents of these articles when discussing invariants and covariants of a system of quadrics. No other changes are made in this later chapter.

In the first part of the chapter on curves and developables, a considerable number of problems on curves defined by parametric equations, mostly concerning curves of order 3 or 4 , is added. This excellent treatment of the projective properties of algebraic curves, the extension of Plücker's numbers to space curves, and the illustrations by means of curves of orders 3 and 4 is still standard, forty years after its first appearance.

In the second part of this chapter the Codazzi formulas and the Frenet formulas have been added, and Staude's construction of confocal quadrics is treated in fairly full outline.

This volume is provided with an index of subject matter and with a list of authors cited.

VIRgIL SNYder.

Oeuvres de Charles Hermite. Publiées sous les auspices de l'Académie des Sciences par Emile Picard. Vol. III. Paris, Gauthier-Villars, 1912. 8vo. 522 pp.

A REviEw of the first two volumes of Hermite's works has been given in volume 13, pages 182-190, and volume 16, pages $370-377$ of this Bulletin. The thirty-nine memoirs which make up the present volume belong to the years 18721880. A fourth volume will contain the remaining papers and bring the work to a close. 
The majority of the papers of this third volume are short notes of a few pages each, and deal for the most part with algebra, the integral calculus, theory of numbers, differential equations, and elliptic functions. Three of these are extracts from Hermite's Cours d'Analyse; another is from his autographed lectures at the Ecole Polytechnique.

By far the most important paper is the celebrated "Applications des Fonctions elliptiques" appearing first in the Comptes Rendus, beginning in 1877, and afterwards in book form in 1885. This memoir occupies more than 150 pages of the present volume, and contains Hermite's epoch making researches on Lamé's differential equation.

The present volume brings another paper of less real importance but of far more sensational nature, namely the one on "La Fonction Exponentielle." Here Hermite shows that $e$, the base of the Naperian logarithms, is indeed a transcendental irrationality. A cruel fate robbed him of the glory of proving that $\pi$ is also transcendental, and yet it would have been but a short step for him to make. In a letter to Borchardt he writes: "Je ne me hasarderai point à la recherche d'une démonstration de la transcendence du nombre $\pi$. Que d'autres tentent l'entreprise, nul ne sera plus heureux que moi de leur succès, mais croyez-m'en, mon cher ami, il ne laissera pas que de leur en côter quelques efforts." Hermite had not long to wait, for nine years later, in 1882, Lindemann brought the long sought proof, and so established the impossibility of "squaring the circle."

The volume is graced with a portrait of Hermite, at about sixty-five. It is a striking likeness; but the kindly look about the eyes will be missed by those who knew him.

\section{James Pierpont.}

Naturwissenschaften und Mathematik im klassischen Altertum.

Von J. L. Heiberg, in Kopenhagen. Mit 2 Figuren im

Text. Teubner, Leipzig, 1912. 102 pp. M. 1.25.

IN our generation there have been three men who were preeminently fitted both by taste and by training to write upon the mathematics of the classical civilization. Others have been able to undertake the task in a satisfactory manner, as witness the labors of scholars like Zeuthen, Loria, and Moritz Cantor, but there always stand out three names of men whose love for Greek science and perfect command of 